\title{
Backward induction or forward reasoning? An experiment of stochastic alternating offer bargaining
}

by Siegfried K. Berninghaus, Werner Güth, Stephan Schosser

No. 42 | JULY 2012

\section{WORKING PAPER SERIES IN ECONOMICS}

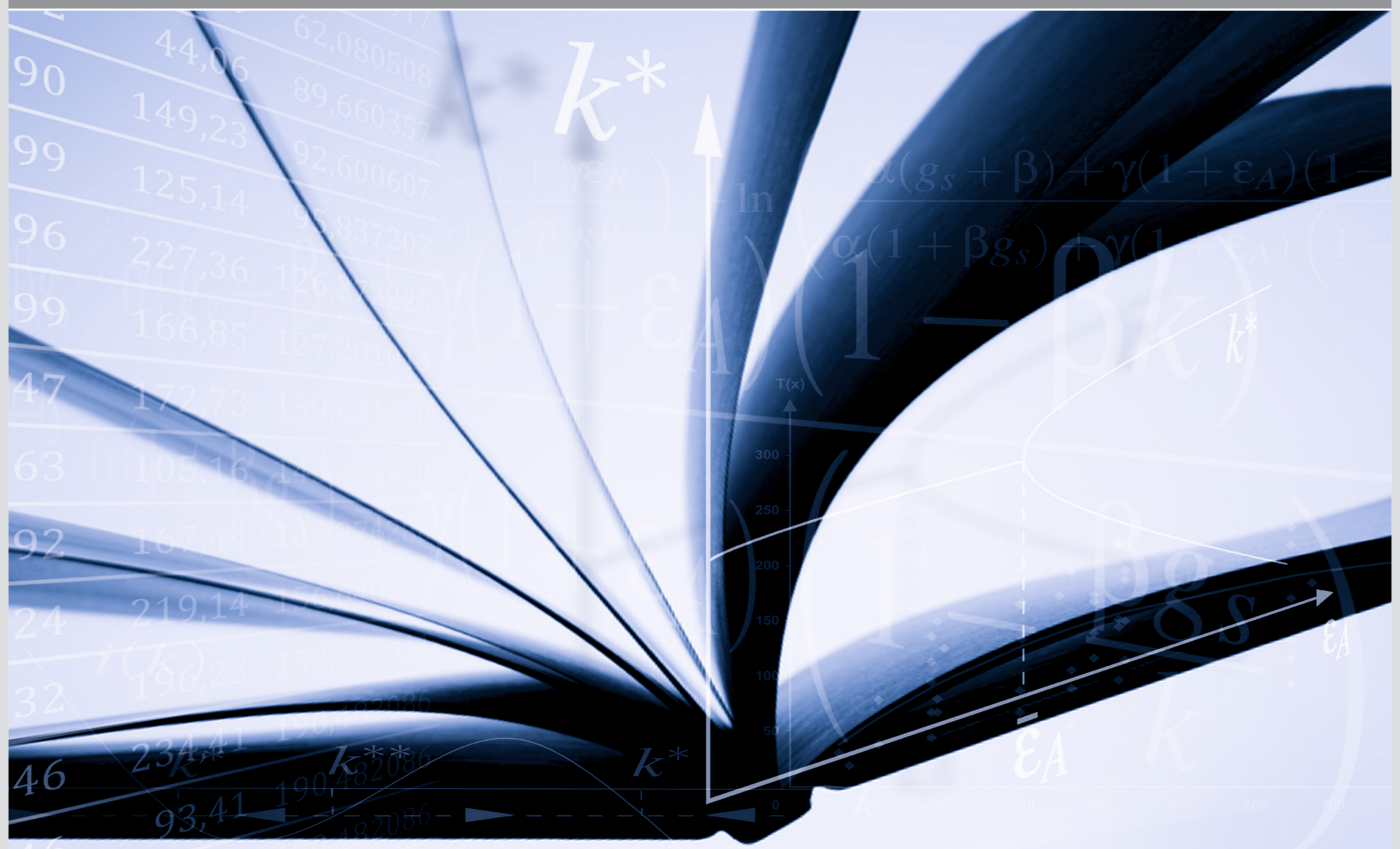




\section{Impressum}

Karlsruher Institut für Technologie (KIT)

Fakultät für Wirtschaftswissenschaften

Institut für Wirtschaftspolitik und Wirtschaftsforschung (IWW)

Institut für Wirtschaftstheorie und Statistik (ETS)

Schlossbezirk 12

76131 Karlsruhe

KIT - Universität des Landes Baden-Württemberg und nationales Forschungszentrum in der Helmholtz-Gemeinschaft

Working Paper Series in Economics

No. 42, July 2012

ISSN 2190-9806

econpapers.wiwi.kit.edu 


\title{
Backward Induction or Forward Reasoning? - An Experiment of Stochastic Alternating Offer Bargaining -
}

\author{
Siegfried K. Berninghaus* Werner Güth ${ }^{\dagger} \quad$ Stephan Schosser ${ }^{\ddagger}$
}

June 2012

\begin{abstract}
Bounded rationality questions backward induction, which however, does not exclude such reasoning when anticipation is easy. In our stochastic (alternating offer) bargaining experiment, there is a certain first-period pie and a known finite deadline. What is uncertain (except for the final period) is whether there is a further period. Whereas backward induction requires information about all later pie sizes and probabilities, forward reasoning is expected to consider only the immediate prospects. Rather than relying only on decision data, we try to assess the cognitive approach such as forward reasoning of backward induction by control of information retrieval. We find that participants who begin with the shortest games before playing possibly longer games, initially resort to backward induction before switching to forward-looking behavior.
\end{abstract}

Keywords: backward induction, forward reasoning, bargaining JEL classification: C70, C72, C91

\section{Introduction}

In alternating offer bargaining one player, the proposer, offers a distribution of the presently distributable pie to the other player, the responder. The responder can then decide whether to accept or reject the offer. If the responder rejects and the period is the terminal one, conflict results; otherwise, the next period begins. Now both players switch roles, i.e., the proposer (responder) from the preceding period is now responder (proposer). Usually one assumes that the distributable pie is smaller than in the preceding period. Conflict means that

\footnotetext{
*Karlsruhe Institute of Technology, Institute for Economic Theory and Statistics, e-mail: siegfried.berninghaus@kit.edu

${ }^{\dagger}$ Max Planck Institute of Economics, e-mail: gueth@econ.mpg.de

$\ddagger$ University of Magdeburg, Chair of Empirical Economics, e-mail: stephan.schosser@ovgu.de
} 
both receive a disagreement payoff. The variant of the game lasting one period is called ultimatum game. Longer lasting games are known as alternating offer games (e.g., Ståhl (1972); Rubinstein (1982)).

In alternating offer games, implausible threats allow for a wide variety of equilibria, similar to the multiplicity of the equilibria in the ultimatum game. However, only one such equilibrium is subgame perfect, i.e., does not rely on implausible threats. One can derive this equilibrium by backward induction: in the last period, the responder will accept any offer marginally above the conflict payoff, and the proposer will offer exactly this amount. In the preceding period, the proposer, who is the responder in the last period, will anticipate this and offer the reduction of the pie from the second-last to the last period to the responder. Applying this principle repeatedly until the first period determines an initial offer which the first responder should accept. In consequence, alternating offer play last for just one period.

Sequential bargaining games are central in experimental economic research and reveal clear differences between theoretically predicted and experimentally observed behavior (see Güth et al. (1982); Binmore et al. (1985) for early experiments and Roth (1995) for a survey). Whereas the intensively studied ultimatum game mainly motivated the ongoing discussion of social preferences (see, e.g., Loewenstein et al. (1989); Fehr and Schmidt (1999); Bolton and Ockenfels $(1998,2000))$, alternating offer bargaining games have recently not attracted as much attention. This is surprising since alternating offer bargaining games with shrinking pies and unique subgame perfect equilibria allow to test aspects of bounded rationality. For only boundedly rational participants backward induction must be substituted by some form of forward thinking when the horizon is rather long. To study when participants switch from backward induction to forward thinking and which form of forward thinking they use, we increase complexity by increasing the number of periods played as well as by studying stochastic rather than deterministic alternating offer games which end with positive probability after a non-terminal period without agreement. Let us review the main former studies before arguing how such a design may help to study such topics experimentally.

Binmore et al. (1985) conducted an alternating offer experiment lasting for two periods which was repeated once. Although initial offers in the first play were close to half of the first pie size, they observed a clear shift toward backward induction play in the repetition and concluded that learning results in offers closer to the theoretical benchmark by backward induction.

In response to Binmore et al. (1985), Güth and Tietz (1986) find that participants do not play the backward induction solution, if the backward induction outcome is unfair.

Neelin et al. (1988) reacted to Binmore et al. (1985) by another set of experiments, varying both the duration and the pie sizes. They found that behavior is neither in line with fairness nor with backward induction. In their experiments, the modal initial offer is the pie size distributable in the second period. ${ }^{1}$

\footnotetext{
${ }^{1}$ Binmore et al. (1988) replied to Neelin et al. (1988).
} 
Ochs and Roth (1989) find that a substantial percentage of first offers is rejected and that several of these rejections were followed by disadvantageous counterproposals. They confirmed that first-period offers lie between the theoretical benchmark and equal division of first-period pies. Binmore et al. (2002) explore experimentally a two-period alternating offer game as well as its subgames and find that the behavior violates both subgame and truncation consistency. $^{2}$

Finally, Johnson et al. (2002) try to separate the impact of three different decision rules in a three-period alternating offer game: (1) instantly offering $40 \%$ of the pie; (2) assuming that the responder in period 1 will offer $50 \%$ of the remaining pie in period 2 and reason back (Stahl and Haruvy (2003)); (3) backward induction. To observe all different "cognitive styles," they monitor when and which information is retrieved throughout the game. They confirm (1) and question backward induction (3) by not observing its necessary information retrieval. In an additional treatment, they let participants interact with robots, playing according to the backward induction solution and observe that this leads to backward induction play.

To sum up, the results are partly contradictory. A convincing and consistent explanation of observed behavior is still missing. But, of course, there may be heterogeneity in playing such games. By monitoring information retrieval, Johnson et al. (2002) demonstrated different attitudes in the same experiment. This heterogeneity could partly result from differences in mental abilities. To explore this in our experiment, participants successively play four different alternating offer games with an increasing number of periods, starting with a two-period game and ending with a five-period game. In this way, we hope to identify individual switching from backward induction to forward reasoning. To vary the difficulty of backward induction, we employ stochastic alternating offer games, i.e., after each non-terminal period without an agreement a random draw determines whether the game continues or conflict results. To access the cognitive styles, participants decide before the first offer which information they want to use during play. This information, for which the participants have to pay, is available throughout the experiment, hopefully revealing what participants react to.

Independent of the length of the stochastic alternating offer game, about a third of all participants resorts to equal splits. Of the remaining participants most rely on backward induction when it is socially acceptable and the game is limited to two periods. They switch to forward-looking behavior when the game lasts for up to three periods. In even longer games, participants resort to equal splits without considering end play behavior.

In section 2, we formally introduce the stochastic alternating offer games. Section 3 describes the experimental protocol. We introduce different reasoning modes from literature in section 4. After describing and analyzing the data statistically in section 5 we conclude in section 6 where we link our main findings

\footnotetext{
${ }^{2}$ Subgame consistency means that subgame play is independent of how the subgame is embedded in the larger game context. Truncation consistency means that play does not change when a subgame is substituted by its solution payoffs (see Selten and Güth (1982)).
} 
to the related literature.

\section{Stochastic Alternating Offer Games with Information Retrieval}

Without loss of generality, the initial pie $\Pi_{1}$ is set equal to 100 . We assume that $\Pi_{1}$ is available with certainty but not the later pies $\Pi_{t}$ for $t>1$. The class $\mathcal{G}$ of stochastic alternating offer games $G$ is defined by

$$
G=\left(T,\left(\Pi_{t}, p_{t}\right)_{1<t \leq T}\right), \quad \text { with } 2 \leq T<\infty
$$

where $T \geq 2$ is the maximum number of periods with alternating offers. The continuation probability $p_{t} \in(0,1)$ specifies how likely it is that, in case of not reaching an earlier agreement, in later periods $t$ with $1<t \leq T$ the amount $\Pi_{t}$, the pie $\Pi_{t}$ in period $t$, can be distributed. With probability $\left(1-p_{t}\right)$ nothing is available in period $t$, meaning that bargaining ends in period $t-1$ without an agreement. Here we restrict attention to shrinking pies $^{3}$ in the sense of $\Pi_{t}>\Pi_{t+1}$ for all $1 \leq t<T$.

In odd (even) $t$, player $1(2)$ proposes the share $\mathcal{O}_{t} \in\left[0, \Pi_{t}\right]$ of the pie $\Pi_{t}$, offered to the other player, who then decides whether to accept or refuse. If she accepts, bargaining ends with the responder earning $\mathcal{O}_{t}$ and the proposer collecting the residual $\Pi_{t}-\mathcal{O}_{t}$. If she refuses, she has to make a counteroffer in the following period $t+1$, provided that $t+1 \leq T$ and that chance allows distributing $\Pi_{t+1}$. Otherwise, the game ends in conflict with conflict payoffs of 0 for both.

Players can voluntarily retrieve information before the first period $t=1$. At this time, players 1 and 2 know only $\Pi_{1}=100$ and $T$ but not yet $\Pi_{t}$ and $p_{t}$ for $t=2, \ldots, T$ where the pie sizes $\Pi_{t}$ are not equidistant and the probabilities $p_{t}$ not constant. For each information, i.e., each information request for $\Pi_{t}$ or $p_{t}$, the player faces costs of 1 , which are subtracted from her earnings. Once an information has been retrieved, it remains available for the whole play ${ }^{4}$ with at most $\mathrm{T}$ alternating offer periods. Players decide initially which information they want to buy. Whereas they can completely neglect probability information, they must buy information about $\Pi_{t}$ when period $t$ is actually reached to state an offer $\mathcal{O}_{t}$ in the range $\left[0 ; \Pi_{t}\right]$. Of course, players can buy this information already before the first period. We intentionally limit all voluntary information requests to the time before $t=1$ to simplify the classification of cognitive styles.

The minor fee (of one token) for each piece of information is mainly imposed to limit information retrieval for the sake of curiosity, which may be especially strong since we do not provide full information after playing. Of course, curiosity may be still strong enough to accept the minor information costs, but at least in

\footnotetext{
${ }^{3}$ In stochastic alternating offer games even increasing pie sizes may render later agreements less efficient when efficiency is measured by expected payoffs.

${ }^{4}$ Here we deviate from Johnson et al. (2002) who control for how often, how long, and in which sequence a certain information is looked up and who provide information at no cost.
} 
later plays, we expect participants to retrieve only information which, according to their cognitive style, they deem necessary.

\begin{tabular}{|c|c|r|r|r|r|}
\hline Period & & \multicolumn{1}{|c|}{$T_{2}$} & \multicolumn{1}{c|}{$T_{3}$} & \multicolumn{1}{c|}{$T_{4}$} & \multicolumn{1}{c|}{$T_{5}$} \\
\hline \hline 1 & $\Pi_{1}$ & 100.0 & 100.0 & 100.0 & 100.0 \\
\hline 2 & $p_{2}, \Pi_{2}$ & $0.6,60.0$ & $0.4,84.0$ & $0.6,61.0$ & $0.5,72.0$ \\
\hline 3 & $p_{3}, \Pi_{3}$ &,-- & $0.6,40.0$ & $0.7,36.0$ & $0.6,42.5$ \\
\hline 4 & $p_{4}, \Pi_{4}$ &,-- &,-- & $0.3,20.0$ & $0.5,29.0$ \\
\hline 5 & $p_{5}, \Pi_{5}$ &,-- &,-- &,-- & $0.7,20.0$ \\
\hline
\end{tabular}

Table 1: Games used in the experiment

In Table 1 we summarize the games used in our experiment, all of which let the pie $\Pi_{t}$ shrink irregularly and probability $p_{t}$ vary across $2 \leq t \leq T$ to render information retrieval worthwhile.

\section{Experimental Protocol}

We conducted the experiment in the experimental laboratory of the Max Planck Institute in Jena ${ }^{5}$ with 248 participants. When recruiting, we ensured that none of them had previously participated in any ultimatum or bargaining experiment.

In each of our 8 sessions, we randomly paired participants and assigned 8 participants to one matching group ( 7 sessions with 4 matching groups, one with 3 matching groups). All participants faced a different participant in each game, changing their role after each game, e.g., participants who were player 1 in the first (and third) game were player 2 in second (and last) game. Each participant played all four bargaining games (see Table 1), starting with shortest horizon $(T=2)$ and increasing the planning horizon after each game. Since each matching group generated one independent result, we obtained altogether 31 independent (matching group) observations.

Participants received a hard copy of the instructions, which were read aloud to make them common knowledge. Then participants played the games using a computer terminal.

After participants had played all four games, we paid them in private. All participants received a show up fee of $€ 2.50$ and an additional $€ 0.50$ to compensate potential losses when buying information and not reaching an agreement. For each point a participant earned, he received €0.05. Participants earned $€ 11.27$ on average (minimum: €3.00, maximum: €15.90). A session lasted approximately 1 hour, including 15 minutes each for reading the instructions and paying participants.

\section{Reasoning Modes}

Let us describe the main reasoning modes, as suggested by the data of earlier experiments as well as our own experiment, whose various predictions will be

\footnotetext{
${ }^{5}$ For all methodological and technical details and the instructions, see Appendix B
} 
tested both by the negotiation data and the information requests.

\subsection{Backward induction}

To calculate the backward induction solution (based on opportunism ${ }^{6}$ ) for a stochastic alternating offer game, assume that the proposer in the last-period offers 0 to the responder. For the game lasting 5 periods (see column " $T_{5}$ " in Table 2) this implies for $t=5$ the offer $\mathcal{O}_{5}^{*}=0$. In $t=4$, the proposer knows that her fellow player will allot the whole pie $\Pi_{5}$ to herself and therefore offer her $\Pi_{5}$ discounted by the continuation probability $p_{5}$, i.e. $\mathcal{O}_{4}^{*}=p_{5} \cdot \Pi_{5}$. The proposer in $t=3$ will anticipate this and offer the difference $\Pi_{4}-\mathcal{O}_{4}^{*}$ discounted by $p_{4}$ to her fellow player. This form of backward reasoning continues until the proposer in $t=1$ derives $\mathcal{O}_{1}^{*}$. The solution play is that player 1 offers $\mathcal{O}_{1}^{*}$, which is then accepted by player 2 , the responder in period $t=1$. Thus - which is typical of alternating offer bargaining with shrinking pies - parties do not alternate in offering agreements but agree immediately and hence efficiently.

Obviously, a player resorting to backward induction needs to know all continuation probabilities and all pie sizes. Table 2 summarizes the backward induction offers for all games in Table 1 . We designed the games such that the backward induction offer $\mathcal{O}_{1}^{*}$ was / would be around 25.0 for all experiments. The exception is $T_{2}$ where $\mathcal{O}_{1}^{*}$ is slightly higher. ${ }^{7}$

\begin{tabular}{|c|r|r|r|r|r|}
\hline Period & & \multicolumn{1}{|c|}{$T_{2}$} & \multicolumn{1}{|c|}{$T_{3}$} & $T_{4}$ & \multicolumn{1}{c|}{$T_{5}$} \\
\hline \hline 1 & $\mathcal{O}_{1}^{*}$ & $\begin{array}{r}0.6 \cdot 60.0 \\
=36.0\end{array}$ & $0.4 \cdot(84.0-24.0)$ & $0.6 \cdot(61.0-21.0)$ & $0.5 \cdot(72.0-21.0)$ \\
& & $=24.0$ & $=24.0$ & $=25.5$ \\
\hline 2 & $\mathcal{O}_{2}^{*}$ & & $0.6 \cdot 40.0$ & $0.7 \cdot(36.0-6.0)$ & $0.6 \cdot(42.5-7.5)$ \\
& & $=0.0$ & $=24.0$ & $=21.0$ & $=21.0$ \\
\hline 3 & $\mathcal{O}_{3}^{*}$ & - & & $0.3 \cdot 20.0$ & $0.5 \cdot(29.0-14.0)$ \\
& & - & - & $=6.0$ & $=7.5$ \\
\hline 4 & $\mathcal{O}_{4}^{*}$ & - & - & $=0.0$ & $=14.0$ \\
\hline 5 & $\mathcal{O}_{5}^{*}$ & - & - & $=0.0$ \\
\hline
\end{tabular}

Table 2: Backward induction offers $\mathcal{O}_{t}^{*}$ for the games in Table 1

\subsection{Equal split}

Since former studies of alternating offer bargaining found evidence for equal split offers (see, e.g., Binmore et al. (1985)), we also expect equal split offers in $t=1$, i.e., $\mathcal{O}_{1}=0.5 \cdot \Pi_{1}=50.0$. A player making an equal split offer would not need any additional information and could therefore refrain from buying any information.

\footnotetext{
${ }^{6}$ Each player is opportunistic in the sense of maximizing her own monetary payoff expectation, which is commonly known. Common knowledge can obviously be weakened since it depends on $T$ how often one has to assume that players know that players know... that both players are opportunistic in this sense.

${ }^{7}$ In a game lasting at most two periods, either $p_{2}$ or $\Pi_{2}$ would need to be very low to reach such a value.
} 


\section{3 (Expectation based) forward reasoning}

Several forward reasoning patterns are possible and partly supported by evidence of former experiments. We give an overview of these patterns and name for easy reference later.

Offer $\left(p_{2}\right) \Pi_{2}$ : Neelin et al. (1988) observe that most proposers (independent of the duration of the game) offer the second-period pie $\mathcal{O}_{1}=\Pi_{2}$ to the first responder, which player 2 , the first responder, accepts. In our games, this corresponds to $\mathcal{O}_{1} \geq p_{2} \Pi_{2}$, where we assume that $\mathcal{O}_{1}$ is not less than half of the first-period pie. ${ }^{8}$ A player offering the second-period pie would only be interested in $\Pi_{2}$. In our experiments, the second-period pie is always above half the size of the first-period pie, i.e., $\Pi_{2}>\Pi_{1} / 2$ holds. Hence, we do not expect to see many participants resorting to this pattern. For $\mathcal{O}_{1}=p_{2} \Pi_{2}$ one would, of course, have to know both $p_{2}$ and $\Pi_{2}$.

Offer $\left(p_{2}\right) \Pi_{2} / 2$ : Johnson et al. (2002) claim that some proposers in the first period expect the responder to offer them half of the second-period pie. By reasoning back, the proposer keeps not only the difference between the first and the second pie for herself, but also half of the second pie. Hence, her offer is only $\mathcal{O}_{1}=\Pi_{2} / 2$ respectively $\mathcal{O}_{1}=p_{2} \Pi_{2} / 2$.

Of course, forward thinking as illustrated by cognitive styles "Offer $\Pi_{2}$ " and "Offer $\Pi_{2} / 2$ " may be questioned by strategic reasoning. Player 1 , for instance, could gain by informing herself about $\Pi_{3}$ and applying her reasoning also to the behavior of player 2. In consequence, she would ask for an even larger fraction of the pie in the first period. The longer a player looks ahead, the lower the offer she will have to make to her fellow player, but the more complex the decision problem will turn out to be. Hence, we expect cognitive styles will involve more periods being employed less often.

\subsection{Socially acceptable forward reasoning}

According to Ochs and Roth (1989), participants perceive offers below a certain threshold as "insultingly low" and reject them. We see similar rejection rates in our experiment (for details see Section 5). If we interpret the alternating offer game as a lottery $\left[p_{r}\left(\mathcal{O}_{1}\right), \mathcal{O}_{1} ; 1-p_{r}\left(\mathcal{O}_{1}\right), 0\right]$ with $p_{r}\left(\mathcal{O}_{1}\right)$ as the rejection probability for offer $\mathcal{O}_{1}$, unfair offers yield low expected payoffs (see Fig. 1 visualizing the expected payoffs). ${ }^{9}$ Interestingly, the expected payoff of the first proposer decreases the lower the first period offer. Only in two cases does this payoff lie above 50 (in games $T_{2}$ and $T_{4}$ for offers in the range $[45 ; 50[$ ).

\footnotetext{
${ }^{8}$ In the deterministic alternating offer games, this would require $\Pi_{2} \leq \Pi_{1} / 2$. Only for such games were offers $\mathcal{O}_{1}=\Pi_{2}$ observed by Neelin et al. (1988) and Güth and Tietz (1986); i.e., first proposers hardly ever offered more than $\Pi_{1} / 2$ to the responder even when $\Pi_{2}>\Pi_{1} / 2$.

${ }^{9}$ To derive probabilities even for less frequent offers, we grouped all offers. The expected payoff is the minimum offer in the group multiplied with the rejection probability in the group. This means the values represent the maximum payoff the first period proposer could expect in the group.
} 
Result 1: First-period offers below 45 do not pay.

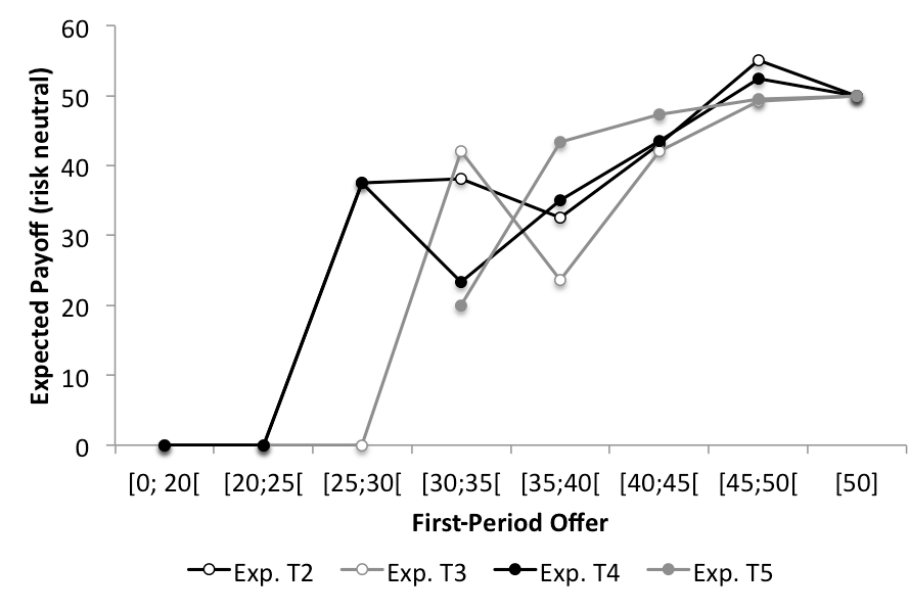

Figure 1: Expected payoff vs. first-period offer

Notice that Figure 1 assumes that all participants correctly anticipate rejection probabilities. In all four games, expected payoffs drop below 40 for offers around 35. In addition, across all games offers between 35 and 40 are rejected with a probability of $50 \%$. Hence, we expect participants to make offers of 35 and higher. Participants resorting to this strategy gather only as much information as they need to justify that offers $\left.\mathcal{O}_{1}\right) \geq 35$ are reasonable.

For the "cognitive styles" Table 3 presents the initial offers $\mathcal{O}_{1}$ suggested by the former (with highest offers displayed first). The games were designed in a way that first-period offers differ as much as possible.

\begin{tabular}{|l|c|c|c|c|}
\hline \multicolumn{1}{|c|}{ Cognitive Style } & $T_{2}$ & $T_{3}$ & $T_{4}$ & $T_{5}$ \\
\hline \hline Offer $\Pi_{2}$ & 60.0 & 84.0 & 61.0 & 72.0 \\
\hline Equal split & 50.0 & 50.0 & 50.0 & 50.0 \\
\hline Socially acceptable & 35.0 & 35.0 & 35.0 & 35.0 \\
\hline Offer $\Pi_{2} / 2$ & 30.0 & 42.0 & 30.5 & 36.0 \\
\hline Offer $p_{2} \Pi_{2}$ & 36.0 & 33.6 & 36.6 & 36.0 \\
\hline Backward induction & 36.0 & 24.0 & 24.0 & 25.5 \\
\hline Offer $p_{2} \Pi_{2} / 2$ & 18.0 & 16.8 & 18.3 & 18.0 \\
\hline
\end{tabular}

Table 3: Predicted first offers $\left(\mathcal{O}_{1}\right)$ for games from Table 1 according to different cognitive styles 


\section{Analysis of Negotiation Data}

Table 4 summarizes medians MD, means M, and standard deviation SD of the first-period offers for all four games (see Table 13 in Appendix A for matching group averages). When comparing these values to our predictions in Table 3 , we see that neither

\begin{tabular}{|l|cc|cc|cc|cc|}
\cline { 2 - 8 } \multicolumn{1}{c|}{} & \multicolumn{2}{c|}{$T_{2}$} & \multicolumn{2}{c|}{$T_{3}$} & \multicolumn{2}{c|}{$T_{4}$} & \multicolumn{2}{c|}{$T_{5}$} \\
\hline \hline MD & 41.0 & 45.0 & 43.0 & 45.0 & \\
\hline M (SD) & 44.2 & $(14.4)$ & 45.0 & $(11.8)$ & 43.3 & $(8.7)$ & 44.8 & $(9.9)$ \\
\hline
\end{tabular}

Table 4: Average offers per experiment

of the values is close to any benchmark solution. "Equal Split" and "Offer $p_{2} \Pi_{2}$ " come closest but are still far away. Similar to Johnson et al. (2002), we assume heterogeneity of cognitive styles, which is confirmed when investigating the distribution of offers (see Table 5). About $30 \%$ of all participants play exactly the equal split solution, another $30 \%$ make an offer between 40 and 45 . Offers in other value ranges are less frequent.

Result 2: Median and mean offers are rather fair and normally deviate considerably from $\mathcal{O}_{1}^{*}$, what is partly justified by the response behavior in the first period with first-period responders often rejecting $\mathcal{O}_{1} \leq 40$.

\begin{tabular}{|c|r|r|r|r|r|r|r|r|}
\hline Offer & \multicolumn{2}{|c|}{$\begin{array}{c}T_{2} \\
\text { Accepted }\end{array}$} & \multicolumn{2}{|c|}{$\begin{array}{c}T_{3} \\
\text { Accepted }\end{array}$} & \# & $\begin{array}{c}T_{4} \\
\text { Accepted }\end{array}$ & \# & $\begin{array}{c}T_{5} \\
\text { Accepted }\end{array}$ \\
\hline \hline$[0 ; 20[$ & 5 & $0.0 \%$ & 3 & $0.0 \%$ & 1 & $0.0 \%$ & - & - \\
\hline$[20 ; 25[$ & 3 & $0.0 \%$ & 1 & $0.0 \%$ & 1 & $0.0 \%$ & 3 & $0.0 \%$ \\
\hline$[25 ; 30[$ & 2 & $50.0 \%$ & 2 & $0.0 \%$ & 2 & $50.0 \%$ & - & - \\
\hline$[30 ; 35[$ & 11 & $54.5 \%$ & 5 & $60.0 \%$ & 9 & $33.3 \%$ & 7 & $28.6 \%$ \\
\hline$[35 ; 40[$ & 4 & $50.0 \%$ & 11 & $36.4 \%$ & 13 & $53.8 \%$ & 9 & $66.7 \%$ \\
\hline$[40 ; 45[$ & 39 & $71.8 \%$ & 30 & $70.0 \%$ & 40 & $72.5 \%$ & 33 & $78.8 \%$ \\
\hline$[45 ; 50[$ & 10 & $100.0 \%$ & 19 & $89.5 \%$ & 21 & $95.2 \%$ & 30 & $90.0 \%$ \\
\hline$[50]$ & 38 & $100.0 \%$ & 43 & $100.0 \%$ & 31 & $100.0 \%$ & 35 & $100.0 \%$ \\
\hline$] 50 ; 100]$ & 12 & $100.0 \%$ & 10 & $100.0 \%$ & 6 & $100.0 \%$ & 7 & $100.0 \%$ \\
\hline \hline All & \multicolumn{7}{|c|}{$78.2 \%$} & \multicolumn{7}{|c|}{$79.0 \%$} & & $78.2 \%$ & & $83.1 \%$ \\
\hline
\end{tabular}

Table 5: Frequency of acceptance of offers in first period

In the first period, $50 \%$ of the offers in the interval $35 \leq \mathcal{O}_{1}<40$ are rejected, and there is a $25 \%$ rejection rate for offers between 40 and 45 , illustrating that participants are pursuing fairness. For games $T_{3}, T_{4}$, and $T_{5}$ "Backward Induction" would therefore have led to no agreement in the first period with $50 \%$ probability. Most of the forward-looking cognitive styles would also confront the first proposer with a high risk of rejection. Although due to $p_{2}$ between 0.4 and 0.6 termination of the game after period 1 is likely, participants risk conflict when they deem first offers unacceptable. 


\begin{tabular}{|c|c|c|c|c|c|c|c|c|}
\hline Period & $\#$ & $\begin{array}{c}T_{2} \\
\text { "Irrational" }\end{array}$ & $\#$ & $\begin{array}{c}T_{3} \\
\text { "Irrational" }\end{array}$ & $\#$ & $\begin{array}{c}T_{4} \\
\text { "Irrational" }\end{array}$ & \# & $\begin{array}{c}T_{5} \\
\text { "Irrational" }\end{array}$ \\
\hline 2 & 12 & $33.3 \%$ & 11 & $0.0 \%$ & 17 & $47.1 \%$ & 10 & $30.0 \%$ \\
\hline 3 & - & - & 0 & - & 4 & $75.0 \%$ & 3 & $33.3 \%$ \\
\hline 4 & - & - & - & - & 1 & $0.0 \%$ & 0 & - \\
\hline 5 & - & - & - & - & & & 0 & - \\
\hline All & 12 & $33.3 \%$ & 11 & $0.0 \%$ & 22 & $50.0 \%$ & 13 & $30.8 \%$ \\
\hline
\end{tabular}

Table 6: Numbers of counteroffers and fractions of "Irrational" counteroffers which would yield less than earlier acceptance, given their acceptance.

Across all games about a third of all counteroffers (see Table 6) assign to the second proposer less than what he would have received by accepting, i.e., a third of all counteroffers are "irrational," a fact especially observed and discussed by Ochs and Roth (1989). This is in line with the evidence of costly punishment (e.g., Fehr and Gächter (2000)), showing that when observing unfair and therefore unacceptable outcomes, participants do not mind to sacrifice own payoff in order to discipline others.

\subsection{Information acquisition}

Let us now focus on voluntary information retrieval before the first period. The information acquired by player 1 and player 2 is quite similar (see Table 7 ). ${ }^{10}$ A test comparing the number of informations requests by player 1 and player 2 reveals significant differences. ${ }^{11}$ About $32 \%$ of all participants do not buy any information and about $10 \%$ of all participants show unusual information requests by restricting interest to pie sizes or continuation probabilities of intermediate periods. ${ }^{12}$ Since these retrieval patterns are infrequent and not in line with any of the cognitive syles discussed above, we neglect them.

Result 3: First-period proposers and responders reveal similar patterns of information retrieval; about one third of all participants does not invest at all in information, whereas those investing in information vary in what they retrieve.

\footnotetext{
${ }^{10}$ This table can be read as follows: The columns represent experiments and players, while each row stands for a certain information pattern. Line $t=2$, e.g., stands for participants gathering information about period 2 (only), lines $t \in[2,3]$ stand for participants gathering information about periods 2 and $3, \ldots \Pi_{t}$ indicates that participants are only interested in pie sizes, $p_{t}$ stands for participants interested in probabilities only, ... To give an example, the value $3.2 \%$ in column " $T_{4}, \mathrm{Pl}$. 2 " and row " $t \in[2,3], \Pi_{t}, p_{t}$ " implies that $3.2 \%$ of all players 2 in game $T_{4}$ retrieved information about all pie sizes and continuation probabilities of periods 2 and 3 and no other information, meaning they informed themselves about $\Pi_{2}, \Pi_{3}, p_{2}$, and $p_{3}$.

${ }^{11}$ Comparison of the fraction of proposers vs. the fraction of responders buying no information per group (31 independent observations, Wilcoxon Test): $T=2: \mathrm{Z}=-0.628, \mathrm{p}=0.530$; $T=3: \mathrm{Z}=-1.404, \mathrm{p}=0.160 ; T=4: \mathrm{Z}=-1.386, \mathrm{p}=0.166 ; T=5: \mathrm{Z}=-0.951, \mathrm{p}=0.342$.

${ }^{12}$ Such patterns occurred at most five times or less often. The only exception is the pattern in which participants bought information concerning the pie size in periods 2 and 3 plus the continuation probability in period $2(T=3: 13$ cases, $T=4: 10$ cases, and $T=5: 14$ cases $)$.
} 


\begin{tabular}{|c|c|c|c|c|c|c|c|c|c|}
\hline & \multicolumn{2}{|c|}{$T_{2}$} & \multicolumn{2}{|c|}{$T_{3}$} & \multicolumn{2}{|c|}{$T_{4}$} & \multicolumn{2}{|c|}{$T_{5}$} \\
\hline & & Pl. 1 & Pl. 2 & Pl. 1 & Pl. 2 & Pl. 1 & Pl. 2 & Pl. 1 & Pl. 2 \\
\hline \multirow[t]{4}{*}{$t=2$} & $\Pi_{t}$ & $24.2 \%$ & $18.5 \%$ & $8.9 \%$ & $14.5 \%$ & $19.4 \%$ & $16.1 \%$ & $12.9 \%$ & $17.7 \%$ \\
\hline & $p_{t}$ & $16.9 \%$ & $18.5 \%$ & $9.7 \%$ & $8.9 \%$ & $7.3 \%$ & $10.5 \%$ & $10.5 \%$ & $10.5 \%$ \\
\hline & $\Pi_{t}, p_{t}$ & $21.0 \%$ & $29.8 \%$ & $15.3 \%$ & $8.9 \%$ & $14.5 \%$ & $11.3 \%$ & $14.5 \%$ & $9.7 \%$ \\
\hline & Sum & $62.1 \%$ & $66.9 \%$ & $33.9 \%$ & $32.3 \%$ & $41.1 \%$ & $37.9 \%$ & $37.9 \%$ & $37.9 \%$ \\
\hline \multirow{4}{*}{$\begin{array}{c}t \in \\
{[2,3]}\end{array}$} & $\overline{\Pi_{t}}$ & - & - & $14.5 \%$ & $16.1 \%$ & $5.6 \%$ & $8.9 \%$ & $5.6 \%$ & $4.8 \%$ \\
\hline & $p_{t}$ & - & - & $4.8 \%$ & $4.0 \%$ & $1.6 \%$ & $1.6 \%$ & $0.0 \%$ & $0.8 \%$ \\
\hline & $\Pi_{t}, p_{t}$ & - & - & $12.1 \%$ & $2.4 \%$ & $1.6 \%$ & $3.2 \%$ & $4.0 \%$ & $3.2 \%$ \\
\hline & Sum & - & - & $31.5 \%$ & $22.6 \%$ & $8.9 \%$ & $13.7 \%$ & $9.7 \%$ & $8.9 \%$ \\
\hline \multirow{4}{*}{$\begin{array}{c}t \in \\
{[2 . .4]}\end{array}$} & $\Pi_{t}$ & - & - & - & - & $4.8 \%$ & $5.6 \%$ & $0.8 \%$ & $0.0 \%$ \\
\hline & $p_{t}$ & - & - & - & - & $2.4 \%$ & $0.8 \%$ & $0.0 \%$ & $0.0 \%$ \\
\hline & $\Pi_{t}, p_{t}$ & - & - & - & - & $0.0 \%$ & $3.2 \%$ & $0.8 \%$ & $0.0 \%$ \\
\hline & Sum & - & - & $\begin{array}{ll}- \\
-\end{array}$ & - & $7.3 \%$ & $9.7 \%$ & $1.6 \%$ & $0.0 \%$ \\
\hline \multirow{4}{*}{$\begin{array}{c}t \in \\
{[2 . .5]}\end{array}$} & $\Pi_{t}$ & - & - & - & - & - & - & $1.6 \%$ & $0.0 \%$ \\
\hline & $p_{t}$ & - & - & - & - & - & - & $0.0 \%$ & $0.0 \%$ \\
\hline & $\Pi_{t}, p_{t}$ & - & - & - & - & - & - & $0.8 \%$ & $0.0 \%$ \\
\hline & Sum & - & - & - & - & - & - & $2.4 \%$ & $0.0 \%$ \\
\hline \multicolumn{2}{|c|}{ No info. } & $37.9 \%$ & $33.1 \%$ & $24.2 \%$ & $33.1 \%$ & $29.8 \%$ & $22.6 \%$ & $33.9 \%$ & $37.9 \%$ \\
\hline \multicolumn{2}{|c|}{ Other } & - & 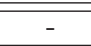 & $10.5 \%$ & $12.1 \%$ & $12.9 \%$ & $16.1 \%$ & $14.5 \%$ & $15.3 \%$ \\
\hline
\end{tabular}

Table 7: Frequency of information acquisition per experiment

Other information acquisition patterns allow for backward induction by acquiring information for period $2(t=2)$, for periods 2 and $3(t \in[2,3])$, for periods 2 to $4(t \in[2,3,4])$ or for periods 2 to $5(t \in[2,3,4,5])$. Participants are interested in both, pie sizes and continuation probabilities $\left(\Pi_{t}, p_{t}\right.$, about $20 \%$ ), or in pie sizes only $\left(\Pi_{t}\right.$ : about $\left.25 \%\right)$. About $14 \%$ of all participants are interested in the continuation probabilities only $\left(p_{t}: 14 \%\right)$ and thus reveal a surprising curiosity.

While in game $T_{3}$ equally many participants are interested in all periods, interest in later periods decreases for the longer games $\left(T_{4}, T_{5}\right)$. In game $T_{5}$, only $2.4 \%$ are interested in the last period $(t=T=5)$. Hence, we conclude that participants rely on forward reasoning and neglect later periods.

Result 4: When the horizon is long as, for example, in game $T_{5}$, information retrieval, as required by backward induction, is rare.

\begin{tabular}{|l|c|c|c|c|c|c|c|c|}
\cline { 2 - 9 } & \multicolumn{2}{c|}{$T_{2}$} & \multicolumn{2}{c|}{$T_{3}$} & \multicolumn{2}{c|}{$T_{4}$} & \multicolumn{2}{c|}{$T_{5}$} \\
& Pl. 1 & Pl. 2 & Pl. 1 & Pl. 2 & Pl. 1 & Pl. 2 & Pl. 1 & Pl. 2 \\
\hline \hline$\Pi_{t}$ & 1.00 & 1.00 & 1.62 & 1.53 & 1.51 & 1.66 & 1.58 & 1.21 \\
\hline$p_{t}$ & 1.00 & 1.00 & 1.33 & 1.31 & 1.57 & 1.25 & 1.00 & 1.07 \\
\hline$\Pi_{t}, p_{t}$ & 2.00 & 2.00 & 2.88 & 2.43 & 2.20 & 3.09 & 2.80 & 2.50 \\
\hline No info. & - & - & - & - & - & - & - & - \\
\hline Other & - & - & 2.46 & 2.40 & 2.63 & 2.70 & 2.44 & 2.89 \\
\hline \hline All & 1.34 & 1.45 & 2.14 & 1.80 & 1.88 & 2.14 & 2.05 & 1.87 \\
\hline
\end{tabular}

Table 8: Information costs per participant 
Table 8 gives an overview of average information costs. While in games $T_{2}$ and $T_{3}$ no significant difference between information costs per participant exists, in games $T_{4}\left(T_{5}\right)$ information costs of player 1 are significantly lower (higher) than the costs of player $2 .{ }^{13}$

\section{$6 \quad$ Reasoning Styles}

Are the offers in line with the cognitive styles discussed above? We focus on the offers in the first period (see Table 9) and first refer to the participants with an "Equal Split" strategy who should not be interested in any information and offer $50 \%$ of the initial pie $\left(\Pi_{1}\right)$. In all four games about 40 participants bought no information, i.e., were potential equal splitters and made offers with a median of 50 (only game $T_{5}$ deviates with a median of 48 ). The individual offers of participants buying no information also show that more than $50 \%$ of them offered around 50 in the first period (see Tables 10-15). The "equal split" mode of reasoning is the reasoning style of about $34 \%$ of all participants.

Result 5: Equal splitters are quite frequent and develop this tendency without any attempt to explore what they could gain by behaving strategically.

Participants playing backward induction have to buy information concerning the pie size $\Pi_{t}$ and the continuation probability $p_{t}$ for all periods of the game. In games $T_{4}$ and $T_{5}$, less than $1 \%$ of all players 1 buy this information (see Table 7 ). In games $T_{2}$ and $T_{3}$, more than $20 \%$ and $10 \%$, respectively, buy this information. When comparing first-period offers of participants buying and not buying all information, those not buying resort to equal split offers significantly more frequently in game $T_{2} \cdot{ }^{14}$ In addition, the average first-period offer of player 1 participants in $T_{2}$ buying $\Pi_{2}, p_{2}$-information is, with 38.81 , (see Table 9) close to the theoretical prediction by backward induction. For game $T_{3}$ we do not find a significant difference in offers ${ }^{15}$ between those participants retrieving no information and those retrieving all information for backward induction. We conclude that about $20 \%$ of participants in game $T_{2}$ resort to backward induction, while we do not find such behavior in any longer game.

Result 6: In line with earlier results (e.g., of Binmore et al. (1985)), in game $T_{2}$ only a significant share of participants behaves according to backward induction by both information retrieval and first-period offer close to its prediction.

Even so, participants interested in both continuation probabilities $p_{t}$ and pie sizes $\Pi_{t}$ of games $T_{4}$ and $T_{3}$ often choose the equal split in the first period. ${ }^{16}$

\footnotetext{
${ }^{13}$ Comparison of information costs of first proposers vs responders per group (31 independent observations, Wilcoxon Test): $T=2: \mathrm{Z}=-1.427, \mathrm{p}=0.154 ; T=3: \mathrm{Z}=-2.529, \mathrm{p}=0.011$; $T=4: \mathrm{Z}=-2.028, \mathrm{p}=0.043 ; T=5: \mathrm{Z}=-1.320, \mathrm{p}=0.187$.

${ }^{14}$ Wilcoxon Test: Obs. $18, \mathrm{Z}=-2.588, \mathrm{p}=0.010$.

${ }^{15}$ Wilcoxon Test: Obs. $10, \mathrm{Z}=-1.612, \mathrm{p}=0.107$.

${ }^{16}$ Wilcoxon Test: $T_{4}$ : Obs. $11, \mathrm{Z}=-1.782, \mathrm{p}=0.075 ; T_{5}$ : Obs. $17, \mathrm{Z}=-1.301, \mathrm{p}=0.193$.
} 


\begin{tabular}{|l|l|rr|rr|rr|rr|}
\cline { 3 - 11 } \multicolumn{2}{c|}{} & \multicolumn{2}{c|}{$T_{2}$} & \multicolumn{2}{c|}{$T_{3}$} & \multicolumn{2}{|c|}{$T_{4}$} & \multicolumn{2}{|c|}{$T_{5}$} \\
\hline \hline \multirow{2}{*}{$\Pi$} & MD (\#) & 40.00 & $(30)$ & 46.00 & $(29)$ & 40.00 & $(37)$ & 40.50 & $(26)$ \\
\cline { 2 - 11 } & M (SD) & 42.33 & $(19.3)$ & 47.45 & $(18.1)$ & 40.13 & $(6.7)$ & 42.04 & $(7.7)$ \\
\hline \hline \multirow{2}{*}{$p$} & MD (\#) & 40.00 & $(21)$ & 45.00 & $(13)$ & 42.00 & $(14)$ & 45.00 & $(13)$ \\
\cline { 2 - 11 } & M (SD) & 42.52 & $(8.5)$ & 46.28 & $(9.6)$ & 44.29 & $(4.8)$ & 44.08 & $(5.6)$ \\
\hline \hline \multirow{2}{*}{$\Pi, p$} & MD (\#) & 40.00 & $(26)$ & 40.00 & $(25)$ & 41.00 & $(20)$ & 44.00 & $(25)$ \\
\cline { 2 - 11 } & M (SD) & 38.81 & $(13.6)$ & 41.56 & $(11.0)$ & 41.55 & $(5.6)$ & 42.36 & $(7.3)$ \\
\hline \hline \multirow{2}{*}{ No info. } & MD (\#) & 50.00 & $(47)$ & 50.00 & $(42)$ & 50.00 & $(37)$ & 48.00 & $(42)$ \\
\cline { 2 - 10 } & M (SD) & 48.21 & $(12.2)$ & 46.27 & $(5.4)$ & 49.62 & $(9.0)$ & 47.33 & $(10.8)$ \\
\hline \hline \multirow{2}{*}{ Other } & MD (\#) & - & $(-)$ & 45.00 & $(18)$ & 40.00 & $(16)$ & 45.00 & $(18)$ \\
\cline { 2 - 10 } & M (SD) & - & $(-)$ & 44.00 & $(8.1)$ & 37.13 & $(9.8)$ & 46.81 & $(14.5)$ \\
\hline
\end{tabular}

Table 9: Offers per information pattern

Hence, we attribute their interest in information to curiosity and not to cognitive styles such as "Offer $p_{2} \Pi_{2}$ " and "Offer $p_{2} \Pi_{2} / 2$."

Finally, we investigate cognitive styles based on pie sizes only, namely "Offer $\Pi_{2}$ " and "Offer $\Pi_{2} / 2$ " by player 1 . As expected (see the evidence of Neelin et al. (1988) and Güth and Tietz (1986)), "Offer $\Pi_{2}$ " has little chance when suggesting $\mathcal{O}_{1}>\Pi_{1} / 2$ (see Tables 10-15: $T_{2}: 13.3 \%, T_{3}: 13.3 \%, T_{4}: 0.0 \%$, and $T_{2}$ : $3.8 \%)$. Cognitive style "Offer $\Pi_{2} / 2$," on the other hand, seems to occur frequently in our experiments. In games $T_{4}$ and $T_{5}$, the offers by players 1 with information about pie sizes are significantly lower than offers of participants retrieving no information. ${ }^{17}$ In games $T_{2}$ and $T_{3}$, we find no such effect, and the offers of these participants (see Tables 10-15) are in line with the theoretical prediction: about $20 \%$ of participants in game $T_{2}$ and $T_{3}$ resort to "Offer $\Pi_{2} / 2$ " in a forward reasoning style based on pie information only.

\subsection{Discussion}

To summarize our results and relate them to the cognitive styles, we crosstable for each game in Table 3 the first-period offers and the information patterns (see Tables 10 to 15 ).

In game $T_{2}$ (see Table 10), $38 \%$ of all participants (compared to $32 \%$ in all games) buy no information, with the majority of them (30 out 47 ) offering 45 or more. We classify these participants as equal splitters. Another group of 13 participants buys no information and offers 40 to 45 , apparently entertaining the idea of a "first mover advantage." Information of only $\Pi_{t}$ or $p_{t}$ leads to no clear deviation from the behavior of those without any information. Participants knowing both $\Pi_{t}$ and $p_{t}$ seem to rely on "Offer $p_{2} \Pi_{2}$ " (offer $\mathcal{O}_{\infty}=36.0$ ), whereas offers below 35 support neither "Offer $p_{2} \Pi_{2} / 2$ " nor "Offer $\Pi_{2} / 2$ ".

Behavioral patterns remain similar in games lasting for three periods $\left(T_{3}\right.$, see Table 11). Although fewer participants buy no information, i.e., 30 compared to 47 in game $T_{2}$, first-period offers reveal the same peaks (around 50 and in the

\footnotetext{
${ }^{17}$ Wilcoxon-Test: $T_{2}$ : Obs. $17, \mathrm{Z}=-0.853, \mathrm{p}=0.394 ; T_{3}$ : Obs. $12, \mathrm{Z}=-1.479, \mathrm{p}=0.139 ; T_{4}$ : Obs. $16, \mathrm{Z}=-2.735, \mathrm{p}=0.006 ; T_{5}$ : Obs. $16, \mathrm{Z}=-2.324, \mathrm{p}=0.020$.
} 


\begin{tabular}{|c|c|c|c|c|c|c|}
\hline & No Info. & $\Pi_{t}$ & $p_{t}$ & $\Pi_{t}, p_{t}$ & Other & All \\
\hline$[0 ; 20[$ & - & 2 & 1 & 2 & - & 5 \\
\hline$[20 ; 25[$ & - & 2 & - & 1 & - & 3 \\
\hline$[25 ; 30[$ & 1 & 1 & - & - & - & 2 \\
\hline$[30 ; 35[$ & 2 & 4 & 1 & 4 & - & 11 \\
\hline$[35 ; 40[$ & 1 & 1 & 1 & 1 & - & 4 \\
\hline$[40 ; 45[$ & 13 & 7 & 8 & 11 & - & 39 \\
\hline$[45 ; 50[$ & 2 & 4 & 2 & 2 & - & 10 \\
\hline$[50]$ & 21 & 5 & 8 & 4 & - & 38 \\
\hline ]50;100] & 7 & 4 & - & 1 & - & 12 \\
\hline All & 47 & 30 & 21 & 26 & 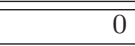 & \\
\hline
\end{tabular}

Table 10: Information patterns vs. first-period offers for $T_{2}$

\begin{tabular}{|c|c|c|c|c|c|c|}
\hline & No Info. & $\Pi_{t}$ & $p_{t}$ & $\Pi_{t}, p_{t}$ & Other & All \\
\hline$[0 ; 20[$ & - & 2 & - & 1 & - & 3 \\
\hline$[20 ; 25[$ & - & - & - & 1 & $\begin{array}{ll}- \\
-\end{array}$ & 1 \\
\hline$[25 ; 30]$ & - & - & - & 1 & 1 & 2 \\
\hline$[30 ; 35[$ & 1 & - & 1 & 2 & 1 & 5 \\
\hline$[35 ; 40[$ & 1 & 2 & 1 & 7 & - & 11 \\
\hline$[40 ; 45[$ & 7 & 9 & 5 & 7 & 2 & 30 \\
\hline$[45 ; 50[$ & 4 & 4 & 4 & 4 & 3 & 19 \\
\hline$[50]$ & 16 & 8 & 5 & 8 & 6 & 43 \\
\hline ]50;100] & 1 & 4 & 2 & 3 & - & 10 \\
\hline All & 30 & 29 & 18 & 34 & 13 & \\
\hline
\end{tabular}

Table 11: Information patterns vs. first-period offers for $T_{3}$

range of 40 to 45) and a similar distribution, supporting equal split strategies. For all other information patterns, i.e., $\Pi_{t}, p_{t}$ or $\left(\Pi_{t}, p_{t}\right)$, the distribution of the first-period offers is similar to those participants without any information. Altogether in game $T_{3}$ no cognitive style other than equal splitting is observable: only $9 \%$ of offers are below 35 suggesting that neither backward induction nor "Offer $p_{2} \Pi_{2} / 2$ " play a major role.

In games $T_{4}$ and $T_{5}$ (see Tables 14 and 15 in Appendix A), participants buying no information have a stronger tendency to split equally than in shorter games.

Depending on the game, median offers were either close to a fair distribution or supported the backward induction solution (see Table 12 for an overview). Nevertheless, for both the fair or the rational benchmark contradicting evidence exists. Furthermore, information retrieval allows us to distinguish different cognitive styles.

Fairness, backward induction, and forward reasoning all occur, but their influence depends on the time horizon. Some participants are fair, i.e., they offer about half of the initial pie, and are not interested in later periods of the bargaining process. Their overall share is about a third and does not change across games. The remaining two thirds of participants resort to other cognitive styles, variants of forward-looking cognitive styles, or backward induction.

We found evidence for changes in cognitive styles being related to the com- 


\begin{tabular}{|l|r|r|c|c|c|c|}
\cline { 2 - 7 } & \multicolumn{1}{c|}{ M of $\mathcal{O}_{1}$} & Amnt. & \multicolumn{1}{c|}{$\Pi_{2}$} & $\Pi_{3}$ & $\Pi_{4}$ & $\Pi_{5}$ \\
\hline \hline Binmore et al. (1985)* & $50.0 \%(25.0 \%)$ & $£ 1.00$ & 25.0 & - & - & - \\
\hline \hline \multirow{3}{*}{ Neelin et al. (1988) } & $25.0 \%-30.0 \%$ & $\$ 5.00$ & 25.0 & - & - & - \\
\cline { 2 - 7 } & $50.0 \%$ & $\$ 5.00$ & 50.0 & 25.0 & - & - \\
\cline { 2 - 7 } & $34.0 \%$ & $\$ 5.00$ & 34.0 & 11.6 & 4.0 & 1.4 \\
\cline { 2 - 7 } & $34.3 \%-36.6 \%$ & $\$ 15.00$ & 25.0 & - & - & - \\
\cline { 2 - 7 } & $34.0 \%$ & $\$ 15.00$ & 50.0 & 25.0 & - & - \\
\hline Ochs and Roth (1989)** & $34.0 \%$ & $\$ 15.00$ & 34.0 & 11.6 & 4.0 & 1.4 \\
\cline { 2 - 7 } & $41.0 \%-45.0 \%$ & $\$ 30.00$ & 40.0 & 16.0 & - & - \\
\cline { 2 - 7 } & $46.0 \%-49.0 \%$ & $\$ 30.00$ & 60.0 & - & - & - \\
\cline { 2 - 7 } & $41.0 \%-45.0 \%$ & $\$ 30.00$ & 60.0 & 36.0 & - & - \\
\hline \hline Johnson et al. (2002) & $40.0 \%-44.0 \%$ & $\$ 5.00$ & 50.0 & 25.0 & - & - \\
\hline \hline Our results & $41.0 \%$ & $€ 5.00$ & 60.0 & - & - & - \\
\cline { 2 - 7 } & $45.0 \%$ & $€ 5.00$ & 84.0 & 40.0 & - & - \\
\cline { 2 - 7 } & $43.0 \%$ & $€ 5.00$ & 61.0 & 36.0 & 20.0 & - \\
\cline { 2 - 7 } & $45.0 \%$ & $€ 5.00$ & 72.0 & 42.5 & 29.0 & 20.0 \\
\hline
\end{tabular}

* The game was played twice. In the second play only player 2 from the first repetition made an offer. The median of the second repetition is shown in brackets. ** The games vary only with respect to $\Pi_{t}$. Here, we focus on the symmetric version only.

Table 12: Median first-period offers in experiments ( $\Pi_{1}$ normalized to 100)

plexity of the game (in game $T_{3}$ twice as many offers are near the backward induction solution compared to game $T_{5}\left(T_{4}\right)$ ). Some form of level-n bounded rationality (Stahl and Haruvy (2003)), as observed by Johnson et al. (2002), is not supported (all offers are just too high).

On the other hand, the conclusion of Ochs and Roth (1989) that participants perceive offers below a certain threshold as "insultingly low" and reject them is justified. In our experiments, participants rejected about $20 \%$ of all offers, ${ }^{18}$ which is comparable to related experiments (Johnson et al. (2002)); especially low offers face a high risk of being rejected, which participants seem to anticipate. When backward reasoning based on the retrieved information suggests an unfair offer, participants seem to stop using such information and rather resort to a fair offer. Offers differ between participants retrieving no information and all other participants ${ }^{19}$ (with the exception of $T_{3}$, suggesting that allowing and monitoring voluntary information retrieval is a promising research method).

\footnotetext{
${ }^{18} T_{2}: 21.8 \% ; T_{3}: 21.0 \% ; T_{4}: 21.8 \% ; T_{5}: 16.9 \%$.

${ }^{19}$ Wilcoxon Test: $T_{2}$ : Obs. $26, \mathrm{Z}=-2.707, \mathrm{p}=0.007 ; T_{3}$ : Obs. $20, \mathrm{Z}=-1.457, \mathrm{p}=0.145 ; T_{4}$ : Obs. $24, \mathrm{Z}=-3.687, \mathrm{p}=0.000 ; T_{5}$ : Obs. $27, \mathrm{Z}=-2.596, \mathrm{p}=0.009$.
} 


\section{References}

Binmore, K., J. McCarthy, G. Ponti, L. Samuelson, and A. Shaked (2002, May). A Backward Induction Experiment. Journal of Economic Theory 104 (1), 4888.

Binmore, K., A. Shaked, and J. Sutton (1985). Testing noncooperative bargaining theory: A preliminary study. The American Economic Review 75(5), $1178-1180$.

Binmore, K., A. Shaked, and J. Sutton (1988). A further test of noncooperative bargaining theory: Reply. The American Economic Review 78(4), 837-839.

Bolton, G. and a. Ockenfels (1998, June). Strategy and Equity: An ERCAnalysis of the Güth-van Damme Game. Journal of mathematical psychology 42(2/3), 215-26.

Bolton, G. E. and A. Ockenfels (2000). ERC: A Theory of Equity, Reciprocity, and Competition. The American Economic Review 90 (1), 166-193.

Fehr, E. and S. Gächter (2000, February). Cooperation and Punishment in Public Goods Experiments. American Economic Review 90(4), 980-994.

Fehr, E. and K. M. Schmidt (1999). A Theory of Fairness, Competition, and Cooperation. The Quarterly Journal of Economics 114 (3), 817-868.

Güth, W., R. Schmittberger, and B. Schwarze (1982). An experimental analysis of ultimatum bargaining. Journal of Economic Behavior \&3 Organization 3, $367-388$.

Güth, W. and R. Tietz (1986). Auctioning ultimatum bargaining positions How to act if rational decisions are unacceptable? In R. Scholz (Ed.), Current Issues in West German Decision Research, pp. 173-185. Frankfurt/Bern/New York: P. Lang Publisher.

Johnson, E., C. Camerer, S. Sen, and T. Rymon (2002, May). Detecting failures of backward induction: Monitoring information search in sequential bargaining. Journal of Economic Theory 104(1), 16-47.

Loewenstein, G. F., L. Thompson, and M. H. Bazerman (1989). Social utility and decision making in interpersonal contexts. Journal of Personality and Social Psychology 57(3), 426-441.

Neelin, J., H. Sonnenschein, and M. Spiegel (1988). A further test of noncooperative bargaining theory: Comment. The American Economic Review 78(4), $824-836$.

Ochs, J. and A. E. Roth (1989). An experimental study of sequential bargaining. The American Economic Review 79(3), 355-384. 
Roth, A. (1995). Bargaining Experiments. In J. Kagel and A. E. Roth (Eds.), Handbook Of Experimental Economics, pp. 253-348. Princeton University Press.

Rubinstein, A. (1982). Perfect Equilibrium in a Bargaining Model Author. Econometrica 50(1), 97-109.

Selten, R. and W. Güth (1982). Game Theoretical Analysis of Wage Bargaining in a Simple Business Cycle Model. Journal of Mathematical Economics 10, 177-195.

Stahl, D. and E. Haruvy (2003). Level-n bounded rationality in two-player twostage games. Journal of Economic Behavior \& Organization 65(1), 41-61.

Ståhl, I. (1972). Bargaining theory. Stockholm: Stockholm School of Economics. 


\section{A Supplementary data}

This appendix gathers supplementary data which might be of interest to the reader but is to extensive for the main paper.

Table 13 summarizes aggregates for all matching groups, i.e., all independent observations. Column 'MD' is the median first-period offer in the matching group, 'M' the mean, and 'SD' the standard deviation.

\begin{tabular}{|c|c|c|c|c|c|c|c|c|}
\hline Gr. & MD & $\begin{array}{l}T_{2} \\
\mathbf{M}(\mathrm{SD})\end{array}$ & MD & $\begin{array}{l}T_{3} \\
\mathbf{M}(\mathrm{SD})\end{array}$ & MD & $\begin{array}{l}T_{4} \\
\mathbf{M}(\mathrm{SD})\end{array}$ & MD & $\begin{array}{l}T_{5} \\
\mathbf{M}(\mathbf{S D})\end{array}$ \\
\hline 1 & 40.0 & $38.0(14.2)$ & 75.0 & $71.5(33.4)$ & 41.5 & $43.0(5.0)$ & 75.0 & $70.5(34.9)$ \\
\hline 2 & 44.5 & $42.3(9.3)$ & 40.0 & $42.5(5.0)$ & 42.5 & $41.0(5.2)$ & 45.0 & $44.5(3.3)$ \\
\hline 3 & 40.0 & $38.8(6.3)$ & 40.0 & $38.8(6.3)$ & 37.5 & $37.5(2.9)$ & 37.5 & $38.5(4.4)$ \\
\hline 4 & 45.0 & $45.0(20.4)$ & 46.5 & $39.5(16.7)$ & 41.0 & $44.5(10.6)$ & 33.5 & $34.3(15.5)$ \\
\hline 5 & 40.0 & $42.5(5.0)$ & 42.5 & $42.8(4.6)$ & 44.5 & $44.8(5.5)$ & 45.0 & $45.0(4.1)$ \\
\hline 6 & 50.0 & $48.0(5.4)$ & 47.5 & $46.3(4.8)$ & 50.0 & $47.8(5.2)$ & 47.5 & $46.3(4.8)$ \\
\hline 7 & 45.0 & $43.8(7.5)$ & 47.5 & $44.3(8.5)$ & 33.0 & $35.3(12.0)$ & 47.5 & $41.8(13.4)$ \\
\hline 8 & 45.0 & $42.5(9.6)$ & 44.0 & $44.5(5.3)$ & 40.0 & $40.0(9.5)$ & 44.0 & $44.5(5.3)$ \\
\hline 9 & 45.0 & $42.5(9.6)$ & 37.5 & $38.8(8.5)$ & 45.0 & $41.3(7.5)$ & 40.5 & $40.0(8.6)$ \\
\hline 10 & 42.5 & $37.5(15.6)$ & 50.0 & $48.8(2.5)$ & 44.0 & $44.5(4.2)$ & 47.5 & $46.3(4.8)$ \\
\hline 11 & 42.5 & $37.5(19.4)$ & 50.0 & $50.3(2.1)$ & 46.0 & $46.8(6.2)$ & 46.0 & $45.8(4.0)$ \\
\hline 12 & 45.0 & $46.3(11.1)$ & 45.0 & $43.8(7.5)$ & 42.5 & $43.0(3.6)$ & 45.0 & $42.8(9.8)$ \\
\hline 13 & 41.0 & $48.0(14.7)$ & 52.5 & $53.0(12.6)$ & 38.5 & $38.0(6.3)$ & 41.5 & $39.5(6.7)$ \\
\hline 14 & 45.0 & $50.0(17.8)$ & 50.0 & $46.3(7.5)$ & 50.0 & $47.0(6.0)$ & 50.0 & $47.5(5.0)$ \\
\hline 15 & 40.0 & $38.8(6.3)$ & 45.0 & $46.3(2.5)$ & 45.0 & $44.5(4.9)$ & 45.0 & $45.5(3.3)$ \\
\hline 16 & 46.0 & $50.5(13.7)$ & 42.5 & $41.3(8.5)$ & 38.0 & $42.8(15.4)$ & 44.5 & $43.5(2.4)$ \\
\hline 17 & 50.0 & $47.5(5.0)$ & 50.0 & $47.5(5.0)$ & 45.0 & $45.0(5.8)$ & 47.5 & $47.6(10.2)$ \\
\hline 18 & 40.0 & $39.5(7.4)$ & 43.0 & $46.5(13.1)$ & 33.5 & $35.3(6.7)$ & 41.5 & $41.3(6.4)$ \\
\hline 19 & 40.0 & $37.5(12.6)$ & 35.0 & $35.0(9.1)$ & 50.0 & $47.5(5.0)$ & 40.0 & $39.3(7.0)$ \\
\hline 20 & 47.5 & $55.0(16.8)$ & 50.0 & $50.0(0.0)$ & 49.5 & $51.0(6.4)$ & 50.0 & $51.3(2.5)$ \\
\hline 21 & 40.0 & $33.8(19.7)$ & 44.0 & $37.0(18.9)$ & 50.0 & $46.3(7.5)$ & 47.5 & $45.0(7.1)$ \\
\hline 22 & 50.0 & $47.5(5.0)$ & 50.0 & $50.5(7.4)$ & 50.0 & $48.0(4.0)$ & 50.0 & $47.5(5.0)$ \\
\hline 23 & 50.0 & $47.0(6.0)$ & 50.0 & $51.3(10.3)$ & 46.5 & $45.8(5.1)$ & 50.0 & $48.0(4.0)$ \\
\hline 24 & 32.5 & $33.8(13.8)$ & 42.5 & $35.0(16.8)$ & 38.5 & $38.0(6.2)$ & 44.5 & $44.5(3.7)$ \\
\hline 25 & 40.0 & $40.0(8.2)$ & 40.0 & $38.8(10.3)$ & 42.5 & $43.8(4.8)$ & 42.5 & $43.8(4.8)$ \\
\hline 26 & 47.5 & $46.3(4.8)$ & 39.5 & $41.0(6.4)$ & 44.5 & $44.8(4.1)$ & 44.0 & $43.3(7.0)$ \\
\hline 27 & 47.5 & $58.8(27.8)$ & 45.0 & $44.3(6.8)$ & 41.0 & $42.8(5.0)$ & 45.5 & $44.3(7.0)$ \\
\hline 28 & 40.0 & $47.5(37.8)$ & 45.0 & $46.3(7.5)$ & 40.0 & $32.3(15.5)$ & 42.5 & $44.0(5.2)$ \\
\hline 29 & 50.0 & $55.0(25.2)$ & 49.5 & $49.3(1.0)$ & 46.5 & $52.0(27.5)$ & 49.0 & $48.3(2.4)$ \\
\hline 30 & 35.0 & $33.8(14.9)$ & 38.0 & $34.0(9.5)$ & 42.5 & $43.8(4.8)$ & 40.0 & $37.5(5.0)$ \\
\hline 31 & 45.0 & $45.0(5.8)$ & 47.0 & $51.0(13.3)$ & 43.0 & $44.0(4.3)$ & 47.0 & $47.5(10.1)$ \\
\hline All & 41.0 & $44.2(14.4)$ & 45.0 & $45.0(11.8)$ & 43.0 & $43.3(8.7)$ & 45.0 & $44.8(9.9)$ \\
\hline
\end{tabular}

Table 13: Offers in first period

Tables 14 and 15 offer the same analyses for game $T_{4}$, and $T_{5}$, respectively, as Tables 10 and 11 in the main paper do for the games $T_{2}$ and $T_{3}$. 


\begin{tabular}{|c|c|c|c|c|c|c|}
\hline & No Info. & $\Pi_{t}$ & $p_{t}$ & $\Pi_{t}, p_{t}$ & Other & All \\
\hline$[0 ; 20[$ & - & - & - & $\begin{array}{lll}- & - \\
-1\end{array}$ & 1 & 1 \\
\hline$[20 ; 25[$ & - & 1 & - & - & - & 1 \\
\hline$\overline{[25 ; 30]}$ & - & 1 & - & - & 1 & 2 \\
\hline$[30 ; 35[$ & - & 5 & - & 2 & 2 & 9 \\
\hline$[35 ; 40[$ & 2 & 3 & - & 5 & 3 & 13 \\
\hline$[40 ; 45]$ & 5 & 17 & 8 & 5 & 5 & 40 \\
\hline$[45 ; 50[$ & 6 & 6 & 1 & 5 & 3 & 21 \\
\hline$[50]$ & 19 & 4 & 4 & 3 & 1 & 31 \\
\hline$] 50 ; 100]$ & 5 & - & 1 & - & - & 6 \\
\hline All & 37 & 37 & 14 & 20 & 16 & \\
\hline
\end{tabular}

Table 14: Information patterns vs. first-period offers for $T_{4}$

\begin{tabular}{|c|c|c|c|c|c|c|}
\hline & No Info. & $\Pi_{t}$ & $p_{t}$ & $\Pi_{t}, p_{t}$ & Other & All \\
\hline$[0 ; 20[$ & - & - & - & - & - & 0 \\
\hline$[20 ; 25[$ & 1 & 1 & - & 1 & - & 3 \\
\hline$[25 ; 30[$ & - & - & $\begin{array}{ll}- \\
-\end{array}$ & $\begin{array}{ll}- \\
-\end{array}$ & - & 0 \\
\hline [30;35[ & 1 & 3 & - & 2 & 1 & 7 \\
\hline$[35 ; 40[$ & 1 & 3 & 2 & 1 & 2 & 9 \\
\hline$[40 ; 45[$ & 8 & 7 & 4 & 9 & 5 & 33 \\
\hline$[45 ; 50[$ & 14 & 4 & 2 & 6 & 4 & 30 \\
\hline$[50]$ & 14 & 7 & 5 & 4 & 5 & 35 \\
\hline$] 50 ; 100]$ & 3 & 1 & - & 2 & 1 & 7 \\
\hline All & 42 & 26 & 13 & 25 & 18 & \\
\hline
\end{tabular}

Table 15: Information patterns vs. first-period offers for game $T_{5}$ 


\section{B Methodology}

\section{B.1 Recruiting}

We recruited all participants for our experiments using ORSEE (Greiner (2004)). In addition to the 32 participants we needed for a session, we recruited 5 additional persons to ensure we could fill all matching groups. We ensured that all recruited persons had never participated in ultimatum or bargaining games before. We made no additional restrictions on the subject pool, i.e., participants came from different fields of study at the Friedrich Schiller University Jena.

\section{B.2 Used software during sessions}

We conducted our experiments in a computerized mode, i.e., we implemented all games using zTree (Fischbacher (2007)). The zTree files are available upon request.

Although we handed out instructions ${ }^{20}$ concerning the game in written form, we displayed the changes before games $T_{3}, T_{4}$ and $T_{5}$ on the participants computer terminals in a one-page PDF using E-nstructions (Schmelz (2011)).

\section{B.3 Structure of one session}

Preparation: Before participants entered the laboratory, we started both zTree on the experimenters' PC and zLeaf on all client PCs. Afterwards we placed the instructions for the first game on the seats of each participant.

Admission: In order of arrival, the participants drew 1 out of 32 numbers from a box. The seats in the laboratory were also numbered from 1 to 32 , and each participant took the seat with the number drawn. After each participant was assigned a seat, a student assistant sent the remaining persons (who arrived at the laboratory) home, handing them $€ 2.50$ to each.

$T_{2}$ : After admission, the student assistant welcomed all participants to the laboratory and asked them to read the instructions: ${ }^{21}$

- "We welcome you to this experiment." (Orig.: "Herzlich willkommen zu diesem Experiment.")

- "Please read the instructions carefully." (Orig.: "Bitte lesen Sie die Anleitung gründlich durch.")

- "If you have any questions, please raise your hand." (Orig.: "Sollten Sie Fragen haben, heben Sie bitte Ihre Hand.")

\footnotetext{
${ }^{20}$ See Appendix B.5 for the instructions in German and a translated version

${ }^{21}$ Instructions and communication were in German. We provide both an English translation and the original text.
} 
After all participants had read the instructions, the student assistant summarized them aloud to make them common knowledge.

- "You have all read the instructions for this experiment." (Orig.: "Sie haben jetzt alle die Anleitung für dieses Experiment gelesen.")

- "I will now briefly summarize the instructions again:" (Orig.: "Ich fasse die Anleitung noch einmal kurz zusammen:")

- "The instructions are the same for all of you." (Orig.: "Die Anleitung ist für alle gleich.")

- "The experiment consists of two periods." (Orig.: "Das Experiment besteht aus zwei Runden.")

- "During each period you are either proposer or responder in alternating order." (Orig.: "In jeder Runde sind sie abwechselnd entweder Anbietender oder Nachfrager.")

- "In each period, the proposer commands an amount he can distribute between himself and his partner." (Orig.: "In jeder Runde verfügt der Anbietende über einen Betrag, den er zwischen sich und seinem Mitspieler aufteilen kann.")

- "The proposer decides how much of this amount he will offer to his partner." (Orig.: "Der Anbietende entscheidet dann, wie viel er von diesem Betrag seinem Mitspieler anbietet.")

- "Then the responder decides whether he accepts the offer." (Orig.: "Darauf entscheidet der Annehmer, ob er das Angebot annimmt.")

- "If the responder accepts the offer, the experiment ends and all receive the amount according to the agreed distribution." (Orig.: "Nimmt der Annehmer das Angebot an, endet das Experiment und alle erhalten den Betrag gemäß der abgestimmten Aufteilung.")

- "If the offer is not accepted, a random draw decides whether the experiment continues. In case of continuation, the next period begins. The responder from the preceding period is now the proposer and vice versa. If the experiment ends due to a random draw, both participants receive a payoff of 0." (Orig.: "Wird das Angebot nicht angenommen entscheidet ein Zufallszug, ob das Experiment fortgeführt wird. Im Fall der Fortführung beginnt die nächste Runde. Der Anbieter aus der Vorrunde ist jetzt der Annehmende und umgekehrt. Endet das Experiment durch den Zufallszug, so erhalten beide Spieler eine Auszahlung von 0.”)

- "If both participants reach no agreement within two periods, the experiment ends and both participants receive a payoff of 0." (Orig.: "Kommt es innerhalb von zwei Runden zu keiner Einigung, so endet das Experiment auch und beide Teilnehmer erhalten eine Auszahlung von 0.”) 
- "The first period is special: In this period you can ex ante buy information concerning the probability that the experiment continues and the amount to distribute for every period. Every information costs you one point." (Orig.: "Die erste Runde hat eine Besonderheit: In dieser Runde können Sie Informationen bzgl. der Wahrscheinlichkeit, dass das Experiment fortgeführt wird, und den aufteilenden Betrag für jede Runde im voraus erfahren. Jede dieser Informationen kostet Sie einen Punkt.")

If, after we summarized the instructions, a participant had further questions, we answered them. Afterwards we started game $T_{3}$.

$T_{3}$ : After game $T_{2}$, we displayed the instructions for game $T_{3}$ on the computer terminal. After all participants had read the instructions, the student assistant gave a short summary:

- "You have all read the instructions for the second experiment." (Orig.: "Sie haben jetzt alle die Anleitung für dieses zweite Experiment gelesen.")

- "I will now briefly summarize the instructions again": (Orig.: "Ich fasse die Anleitung noch einmal kurz zusammen:")

- "Other than the preceding experiment, this experiment ends after a maximum of 3 periods." (Orig.: "Anders als das vorhergehende Experiment endet dieses Experiment nach maximal 3 Perioden.")

- "You play with a participant you have not interacted with before. In addition, the amounts to be distributed and the probabilites for a subsequent period may change compared to the preceding experiments." (Orig.: "Sie spielen dieses Experiment mit einem Teilnehmer mit dem Sie vorher noch nicht interagiert haben. Zusätzlich können sich die aufzuteilenden Beträge und die Wahrscheinlichkeit für eine Folgeperiode gegenüber den vorangegangenen Experimenten ändern.")

If, after summarizing the instructions, a participant had further questions, we answered them. Afterwards, we started game $T_{4}$.

$T_{4}$ and $T_{5}$ : The procedure for games $T_{4}$ and $T_{5}$ was identical to the procedure of $T_{3}$, except that we instructed participants they were now playing the third (last) experiment and that the experiment lasted up to 4 (5) periods. When summarizing the instructions of game $T_{5}$, we also informed participants that they would receive their payoffs afterwards.

- "After this experiment, you will receive your payoff." (Orig.: "Nach diesem Experiment werden Sie ihre Auszahlung erhalten.")

Payment: After game $T_{5}$ we paid all participants. After the payment the participants left the laboratory. 


\section{B.4 Matching}

In the beginning of each session, we assigned all participants to one matching group for the whole session. Each matching group consisted of 8 participants, and all participants were internally numbered from 1 to 8 . This internal numbering did not change throughout the session and was used to build (proposer,responder)- pairs. Table 16 summarizes the matching. For example, the participant internally numbered 1 played with participant 8 in game $T_{2}$, with participant 6 in game $T_{3}, \ldots$

\begin{tabular}{|l|r|r|r|r|r|r|r|r|}
\cline { 2 - 9 } & \multicolumn{2}{|c|}{$T_{2}$} & \multicolumn{2}{c|}{$T_{3}$} & \multicolumn{2}{c|}{$T_{4}$} & \multicolumn{2}{c|}{$T_{5}$} \\
& Prop. & Resp. & Prop. & Resp. & Prop. & Resp. & Prop. & Resp. \\
\hline \hline Pair 1 & 1 & 8 & 6 & 1 & 1 & 4 & 2 & 1 \\
\hline Pair 2 & 7 & 2 & 2 & 5 & 3 & 2 & 4 & 3 \\
\hline Pair 3 & 3 & 6 & 8 & 3 & 5 & 8 & 6 & 5 \\
\hline Pair 4 & 5 & 4 & 4 & 7 & 7 & 6 & 8 & 7 \\
\hline
\end{tabular}

Table 16: Matching of participants in one matching group

All participants having odd internal numbers were proposer in games $T_{2}$ and $T_{4}$, all participants having even internal numbers were proposer in games $T_{3}$ and $T_{5}$. In this way, we ensured that no participants had the same role in the first period of two subsequent experiments.

\section{B.5 Instructions}

In this subsection, we print our instructions. We only provide an English translation to stay within the space limitation. We send the German original to the interested reader upon request.

\section{B.5.1 English Instructions - First Experiment}

Welcome to this experiment and thank you very much for your participation. You receive $€ 2.50$ for showing up in time. During the experiment you can earn additional money. Please stay quiet and switch off your mobile phones and carefully read the instructions - which are the same for all. Communication between participants is not allowed. If you do not follow these rules, we have to exclude you from the experiment and any payment. If you have a question, please raise your hand, an experimenter will then come to you and answer your question in private.

The amount of $€ 2.50$ for showing up in time as well as every additional amount you earn during the experiment will be paid to you in cash at the end of the experiment. The payment will be made in private. No other participant will know the amount of your payment. Your payment depends on your own decisions and the decisions of other participants. The payment in the experiment is measured in points. The points you earn during the experiment will be converted into euro at the end of the experiment and paid to you. The conversion rate is given at the end of this document. You and all other participants make their decisions independent of others using a computer terminal. 


\section{Course of the experiment}

During each of the total of four experiments you interact with another participant which we call your partner. Your partner changes from experiment to experiment but not during one experiment. With your partner you bargain during several (at least two) periods over an amount in points. To do so, you are assigned to one role in the beginning of each period: the proposer or the responder. If you are proposer in one period, your partner is responder and vice versa. Depending on your role, you will see different screens.

\section{Course of one period}

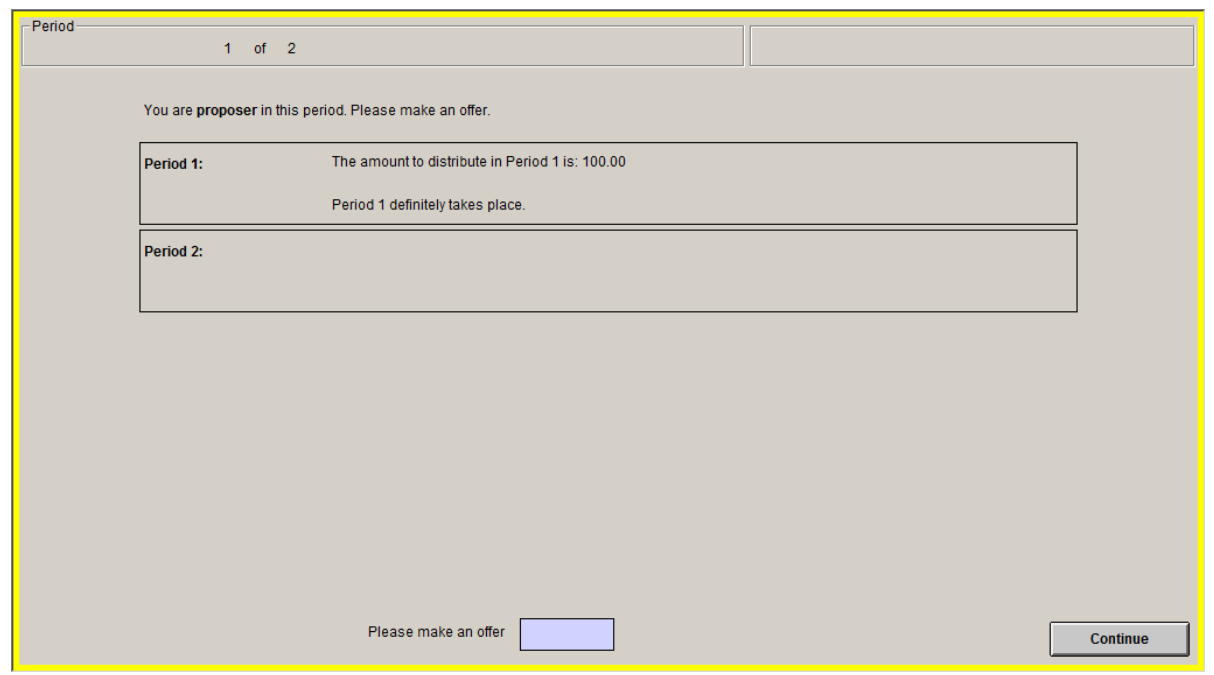

Figure 2: Offer dialog

In the beginning of one period, the proposer is the first to decide. As proposer your screen is similar to the screen in Figure 2. On this screen you see the current period in the upper left area. Below you see all information you know. In the lower area of the screen, you see a box. Into this box you enter the amount you want to offer your partner. If your partner accepts the offer, you receive the amount distributable in this period minus the offer you entered here. After you entered an amount click "Continue". You now have to wait for your partner to decide about acceptance or rejection of your claim.

As responder you have to wait until your partner makes his offer. Then you see a screen similar to the screen in Figure 3. At the top to the left, you see the current period. Below you see all the information, you know. In the lower area of the screen, you see the offer of your partner. You can decide whether you accept the offer or reject it. If you accept the offer, the experiment ends, and the proposer is informed of the acceptance. 


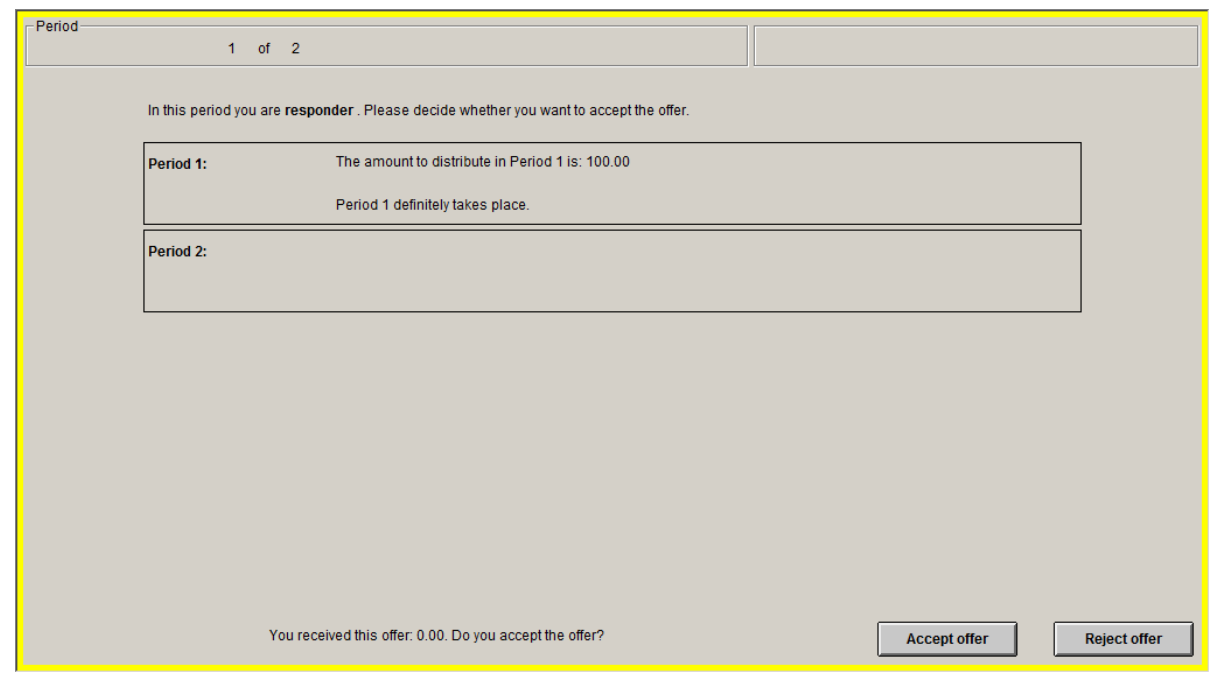

Figure 3: Response dialog

If you reject the offer, the experiment continues with a fixed probability p. In particular, we generate a random number between 0 and 1 . If this number is above $\mathrm{p}$, the experiment ends; otherwise, it continues.

If the experiment continues, you and your partner switch roles, and the next period of the experiment begins. Except for the changed roles, the rules for this period are identical to those of the just finished period.

If you and your partner do not reach an agreement until the end of the last period, both of you receive 0 points.

\section{Specifics of the first period}

The first period is different compared to all following periods. In the beginning of the first period, you see an information screen before the normal screens are shown (see Fig. 4).

This screen consists of one box for every potential period. In the box for period 1, you see the amount which is distributed in the first period. For all subsequent periods this box consists of two buttons. By clicking the upper button, you are informed of the amount to distribute in this period. By clicking the lower button, you get to know the probability p, with which the experiment continues in this period if you have not reached an agreement with your partner before. For each click on a button you face costs of 1 point. You can click as many buttons as you like. For example, you can click no button, click one button, ... or click all buttons. As soon as you click one button, you see the corresponding information. This information is accessible for you in this period and all subsequent periods. As soon as you have all the information you are interested in, please click "Continue" to begin bargaining. 


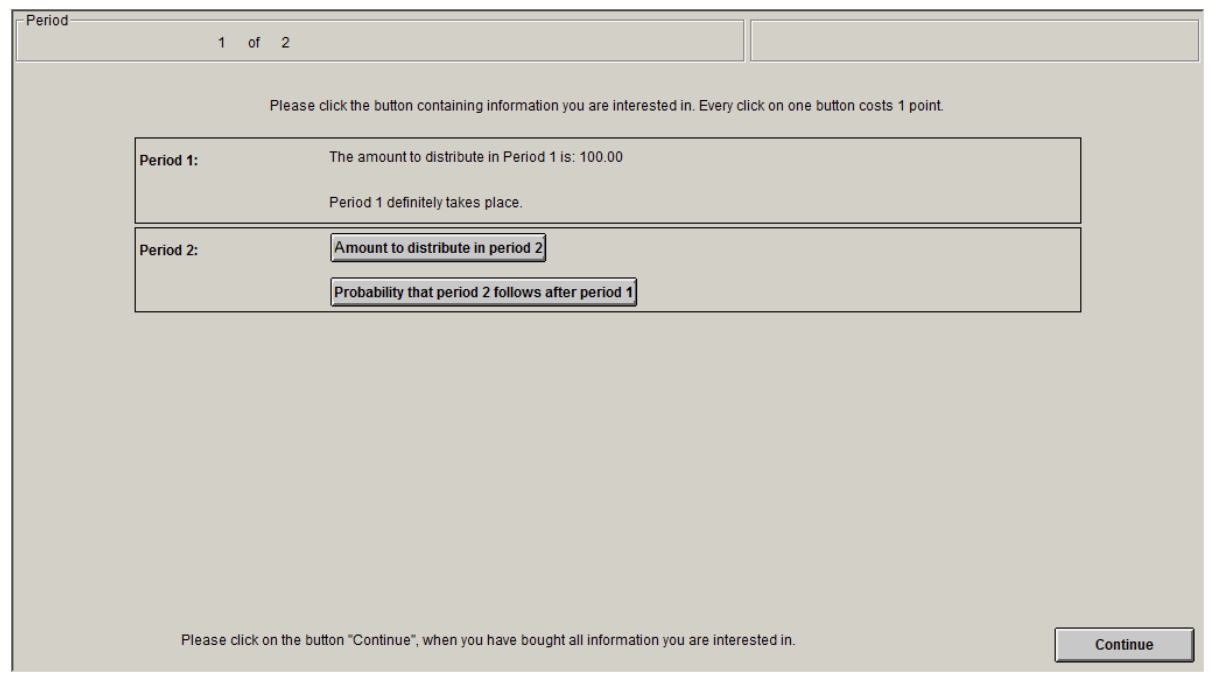

Figure 4: Information at the beginning of the first period

As you need to know the amount to distribute in each period, you are informed of this amount as soon as the corresponding period begins. This also results in costs of 1 point, as long as you have not bought this information before. But costs only arise if the corresponding period is reached. In addition, the amount you and your partner distribute declines from period to period, i.e., early agreements are beneficial.

\section{Type and number of experiments}

You will participate in four experiments, which all follow the description above. The experiments only differ in the maximum number of periods, the amounts to distribute, and the probabilities for one period. The first experiment lasts for up to 2 periods.

\section{Payment}

After the fourth experiment, you are paid. Your payoff is as follows:

$+€ 2.50$ for showing up in time

$+€ 0.50$ to compensate potential losses after buying information

+ Allotment of the distributed amount in the first experiment

- Costs for information in the first experiment

+ Allotment of the distributed amount in the second experiment

- Costs for information in the second experiment

+ Allotment of the distributed amount in the third experiment

- Costs for information in the third experiment 
+ Allotment of the distributed amount in the forth experiment

- Costs for information in the forth experiment

During the experiments costs for information and the distributed amount are shown in points. For your payoff the points are converted into euro. The conversion rule is:

$$
1 \text { Point }=0.05 \text { euro }
$$

Please consider that it is possible that you and your partner do not reach an agreement during the experiment. In this case, you may incur a loss by buying information. To compensate this potential loss, you receive another $€ 0.50$.

We round your payoff to the closest amount divisable by $€ 0.10$.

\section{B.5.2 English Instructions - Later Experiments}

The instructions for game $T_{3}$ are as follows:

The first experiment is now over. You will start the second experiment in an instant. It differs from the preceding experiment in the following points:

- The experiment lasts for a maximum of 3 periods.

- The amounts to distribute may change compared to the preceding experiment.

- The probabilities that one period follows another, may change compared to the preceding experiment.

- For this experiment you are assigned a random new partner you have not yet interacted with.

The instructions of game $T_{4}\left(T_{5}\right)$ were equivalent to these instructions (except for the information that the experiment lasted for 4 (5) periods and that the participant started the third (forth) experiment. In addition, the instructions of game $T_{5}$ were extended by the following hint:

After this experiment you are paid off. Please remain seated until we call you up for your payment. 


\section{References of Appendix}

Fischbacher, U. (2007). z-Tree: Zurich toolbox for ready-made economic experiments. Experimental Economics 10(2), 171-178.

Greiner, B. (2004). The Online Recruitment System ORSEE 2.0 - A Guide for the Organization of Experiments in Economics.

Schmelz, K. (2011). E-nstructions: A Tool for Electronic Instructions in Laboratory Experiments. 


\section{Working Paper Series in Economics}

recent issues

No. 42 Siegfried K. Berninghaus, Werner Güth, Stephan Schosser: Backward induction or forward reasoning? An experiment of stochastic alternating offer bargaining, July 2012

No. 41 Siegfried Berninghaus, Werner Güth, King King Li: Approximate truth of perfectness - an experimental test, June 2012

No. 40 Marten Hillebrand and Tomoo Kikuchi: A mechanism for booms and busts in housing prices, May 2012

No. 39 Antje Schimke: Entrepreneurial aging and employment growth in the context of extreme growth events, May 2012

No. 38 Antje Schimke, Nina Teichert, Ingrid Ott: Impact of local knowledge endowment on employment growth in nanotechnology, February 2012

No. 37 Siegfried K. Berninghaus, Lora Todorova, Bodo Vogt: A simple questionnaire can change everything - are strategy choices in coordination games stable?, December 2011

No. 36 Matthias Duschl, Antje Schimke, Thomas Brenner, Dennis Luxen: Firm growth and the spatial impact of geolocated external factors - empirical evidence for German manufacturing firms, November 2011

No. 35 Mirja Meyborg: The impact of West-German universities on regional innovation activities - a social network analysis, October 2011

No. 34 Tom Broekel, Antje Schimke, Thomas Brenner: The effect of cooperative R\&D subsidies and subsidized cooperation on employment growth, October 2011

No. 33 Stephan Schosser and Bodo Vogt: The public loss game - an experimental study of public bads, August 2011

No. 32 Antje Schimke and Thomas Brenner: Temporal structure of firm growth and the impact of R\&D, July 2011 